\title{
Deep aspirations: towards a sustainable offshore Blue Economy
}

\author{
Camilla Novaglio $(\mathbb{D} \cdot$ Narissa Bax $(\mathbb{D} \cdot$ Fabio Boschetti (1) - Gholam Reza Emad (1) • \\ Stewart Frusher (1) - Liam Fullbrook • Mark Hemer (i) - Sarah Jennings (i) •

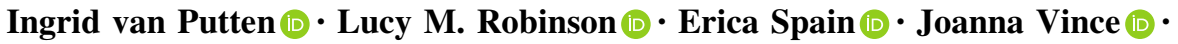 \\ Michelle Voyer (i) - Graham Wood (1) - Elizabeth A. Fulton $(\mathbb{D}$
}

Received: 11 April 2020/Accepted: 21 November 2020/Published online: 21 January 2021

(C) Crown 2021

\begin{abstract}
The ocean economy is experiencing rapid growth that will provide benefits but will also pose environmental and social risks. With limited space and degraded resources in coastal areas, offshore waters will be a particular focus of Blue Economy expansion over the next decade. When emerging and established economic sectors expand in offshore waters (within national Exclusive Economic Zones), different potential Blue Economy opportunities and challenges will arise. Following a series of interdisciplinary workshops, we imagine two technically possible futures for the offshore Blue Economy and we identify the actions required to achieve the more sustainable outcome. Under a business as usual scenario the focus will remain on economic growth, the commodification of nature, the dominance of private over public and
\end{abstract}

Electronic supplementary material The online version of this article (https://doi.org/10.1007/s11160-020-09628-6) contains supplementary material, which is available to authorized users.

C. Novaglio $(\bowtie) \cdot$ M. Hemer · I. van Putten ·

E. A. Fulton

CSIRO, Oceans and Atmosphere, Hobart,

TAS, Australia

e-mail: camilla.novaglio@gmail.com

C. Novaglio $\cdot$ N. Bax $\cdot$ S. Frusher .

L. Fullbrook - S. Jennings - I. van Putten .

J. Vince - G. Wood - E. A. Fulton

Centre for Marine Socioecology, Hobart,

TAS, Australia cultural interests, and prioritisation of the interests of current over future generations. A more sustainable scenario would meet multiple UN Sustainable Development Goals and ensure inclusive economic developments, environmental sustainability, and fair and equitable access to resources and technologies across users, nations, and generations. Challenges to this more sustainable future are a lack of infrastructure and technology to support emerging offshore sectors, limited understanding of environmental impacts, inequitable outcomes, and a lack of planning and governmental oversight. Addressing these challenges will require a shift in societal values, a more balanced allocation of funding to offshore activities, transparency in information sharing between industries and across nations, and adjustment of international legal and institutional mechanisms. The sustainable and equitable offshore Blue Economy we envisage is achievable and provides a unique opportunity to build global capacity and partnership.

C. Novaglio $\cdot$ N. Bax $\cdot$ S. Frusher $\cdot$ E. Spain Institute for Marine and Antarctic Studies, University of Tasmania, Hobart, TAS, Australia

F. Boschetti · L. M. Robinson CSIRO, Oceans and Atmosphere, Perth, WA, Australia

G. R. Emad Australian Maritime College, University of Tasmania, Launceston, TAS, Australia 


\section{Graphic abstract}

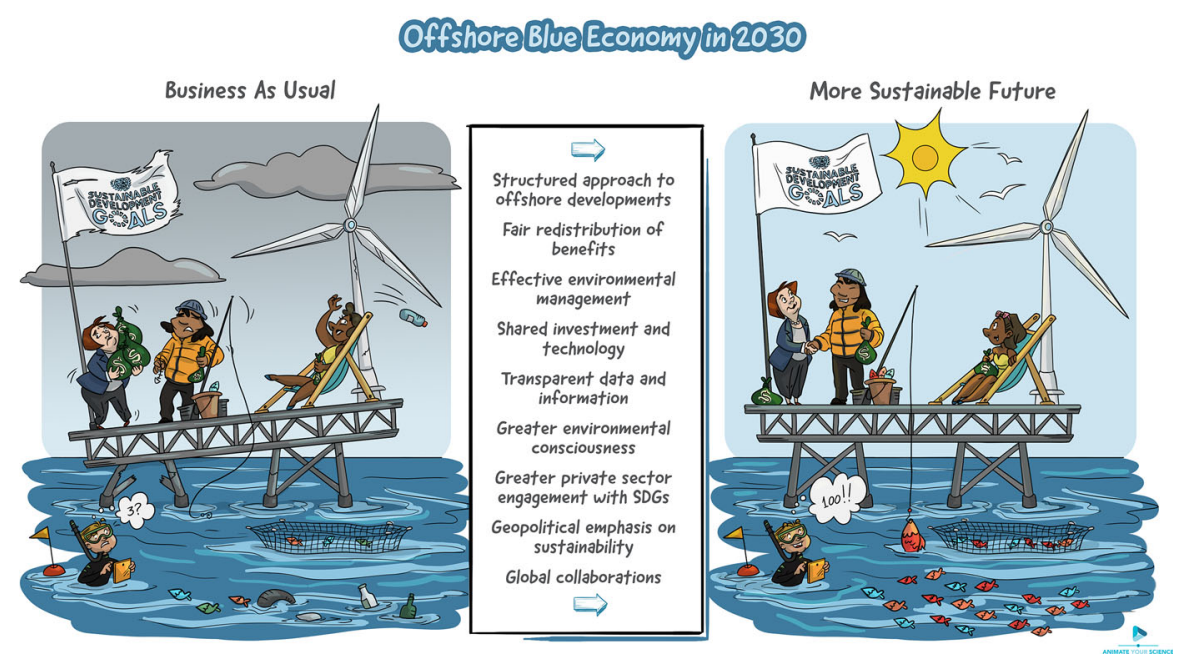

Keywords Equity - Future Seas · Industry · Interdisciplinary research $\cdot$ Ocean $\cdot$ Sustainable Development Goals

\section{Introduction}

The worldwide ocean economy is experiencing rapid growth (Jouffray et al. 2020). It is already valued at around USD 1.5 trillion per year (2010 estimates) and is projected to more than double by 2030 (OECD 2016, 2019). As space on land becomes increasingly crowded and terrestrial resources reach their sustainable limits, the ocean will play a key role in providing goods and services for global populations (OECD 2016; Nyström et al. 2019; United Nations, Department of Economic and Social Affairs, Population Division 2019). Increased economic activity in the ocean will offer benefits, however it will also pose

L. Fullbrook

School of Social Sciences, University of Tasmania,

Hobart, TAS, Australia

L. M. Robinson

Oceans Graduate School, University of Western Australia,

Perth, WA, Australia

J. Vince

School of Social Sciences, University of Tasmania,

Launceston, TAS, Australia important environmental risks that need to be mitigated (Jouffray et al. 2020), and it will likely be accompanied by social, distributional, legal, political, and technological challenges (Kraemer 2017; Hemer et al. 2018; Cisneros-Montemayor et al. 2019; OECD 2019; Voyer et al. 2018). The 'Blue Economy' is a term that has increasingly come to represent the range of economic sectors and related policies that, if coordinated and integrated, could ensure socio-economic and environmentally sustainable ocean resource use (World Bank 2017).

The ocean uses, governance instruments and regulatory frameworks which underpin the Blue Economy are likely to differ between ocean zones and jurisdictions (Garland et al. 2019; Jouffray et al. 2020). The scope of Blue Economy activities can be divided into three broadly recognized ocean zones (Fig. 1):

(i) Coastal waters: usually within $12 \mathrm{~nm}$ from the shore (UN General Assembly 1982). This is an often crowded zone where national and

M. Voyer

Australian National Centre for Ocean Resources and Security (ANCORS), University of Wollongong, Wollongong, NSW, Australia

G. Wood

School of Humanities, University of Tasmania, Launceston, TAS, Australia 
sub-national legislations regulate different ocean uses, competition over space and resources is already high, and degradation is most evident (Jackson et al. 2001; Pandolfi et al. 2003; Halpern et al. 2019; Bax et al. 2020a).

(ii) Offshore waters: adjacent to the coastal zone and stretching from $12 \mathrm{~nm}$ from the shore to the extent of the Exclusive Economic Zone of 200 nm (UN General Assembly 1982). This zone faces many spill-over effects and economic activities from the coastal waters. Countries around the world are formally resolving and delimiting their maritime boundaries and increasingly turning their attention towards the resources contained within these boundaries (e.g. see Patil et al. 2018). However, legislation is often lacking, fragmented or inadequate for the new uses of this zone (e.g. Stuiver et al. 2016).

(iii) Areas beyond national jurisdiction: outside of the $200 \mathrm{~nm}$ EEZ, and also often referred to as the high seas (water column) and the Area (seabed) (UN General Assembly 1982). At present, negotiations are underway to develop or adapt existing international laws in these areas in order to regulate resource use, whilst also maintaining the principles of freedom of navigation (Mickelson 2019) and the continued recognition of seabed resources as the common heritage of mankind (Taylor 2014).

Offshore waters are likely to be a particular focus of Blue Economy expansion over the next decade. This is because coastal waters are crowded and industrial exploitation in areas beyond national jurisdiction poses important logistical and economic challenges. The development of offshore industries is already growing strongly. For example, between 2010 and 2020 there was a 30\% expansion of offshore wind energy production. This was mainly driven by anchored installations, but floating platforms for deployment in deeper waters are also becoming more common (following a pattern seen in oil and gas exploration many years previously). In June 2020, the Ocean Renewable Energy Action Coalition (OREAC) announced its goal of providing $10 \%$ of the world's electricity (approximately $1400 \mathrm{GW}$ ) via offshore wind by 2050. Meeting this goal given current zoning and physical constraints means many more developments will occur offshore within the next decade, with offshore applications already occurring in Northern Europe, China, Japan, Turkey, Brazil and Australia. Similarly, the pressure to increase seafood production by aquaculture has seen a small but growing number of offshore installations deployed in the EEZs of Norway and China, with interest also growing in southern hemisphere countries such as Chile and Australia.

The specific appeal of offshore waters is the available space for potential expansion. For instance, aquaculture is expected to provide around $62 \%$ of aquatic foods by 2030 (World Bank 2017), but most of the current production is on land and in coastal waters where space for expansion is limited. This has led governments, industry and academia to consider offshore sites as a potential solution to such limitations (Hoegh-Guldberg et al. 2019a). Development of infrastructure and service industries, including marine transportation (Pomeroy et al. 2006) and offshore harbours, would be needed to service offshore production sites. A growing marine sector generally, will further drive an increase in demand for energy. With a need to decarbonise the global economy, this growth provides additional incentive for greater uptake of offshore renewable energy technologies (Appiott et al. 2014; Rockström et al. 2017; Hoegh-Guldberg et al. 2019a).

Offshore areas also provide access to an attractive range of resources over which coastal states maintain sovereign rights. Extensive deposits of mineral bearing seafloor massive sulphides, cobalt-rich ferromanganese crusts and phosphorites are located within offshore waters (especially in the Indian and Pacific Ocean basins; Hein et al. 2013). These deposits contain metals such as copper, zinc, gold, silver, nickel and cobalt, as well as many rare earth elements, and their volume is greater than that of accessible terrestrial deposits (Toro et al. 2020). This is important given the demand for metals in modern economies. For example, growth in renewable energy use will increase demand for essential minerals that are used in storage batteries (Hein et al. 2013; Buchholz and Brandenburg 2018). The European Commission estimates that $10 \%$ of world mineral supply may come from the seafloor by 2030 (European Commission 2012), and seafloor mining activities are currently occurring in some countries' offshore waters (Miller 
Fig. 1 Ocean zones for the purpose of this paper and in relation to the United Nation Convention of the Law of the Seas (UNCLOS; UN General Assembly 1982). Figure adapted from Geoscience Australia (http://www.ga.gov.au/ ausgeonews/ ausgeonews200903/limits. jsp)

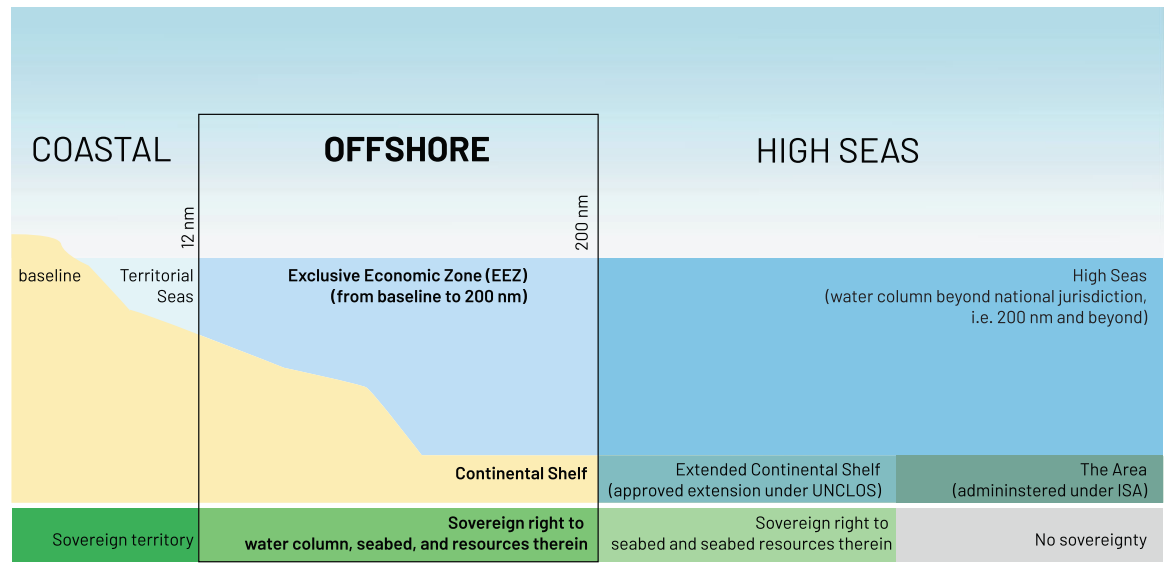

et al. 2018). These activities may increase as mineral resource demands grow, land mineral resources become scarce, and social, economic, political, and technological thresholds are met (Teske et al. 2016; Miller et al. 2018). Examples of these thresholds are increases in minerals prices and the development of deep sea mining tools to cover the different phases of mineral extraction and processing (Hein et al. 2013; Ribeiro et al. 2020).

Many coastal states have recognised the potential of offshore waters to deliver economic growth, and this has led to increased research and development activity addressing the logistical and technical challenges of working in this area. For example, development of multi-use offshore platforms to integrate offshore activities is a particular focus of current research and testing (Zanuttigh et al. 2016; Dalton et al. 2019; Lagasco et al. 2019) and individual sectors, such as aquaculture, are actively developing offshore options.

The growth in offshore economic activity brings additional environmental risks, including further exacerbating climate change, pollution (e.g. plastics and chemicals) and habitat degradation (Halpern et al. 2019; Pörtner et al. 2019; Egger et al. 2020; see also Trebilco et al. 2020, Melbourne-Thomas et al. 2020 and Willis et al. 2020, part of this special issue). Marine ecosystems are inter-connected, and the full cumulative implication of emerging offshore developments is uncertain (Halpern et al. 2019). Nevertheless, the Blue Economy, if governed correctly, can present sustainable and equitable solutions to the current pressures faced in the oceans (Hoegh-Guldberg et al. 2019a, b). Sustainable development of offshore areas has the potential to reduce pressures on coastal and terrestrial systems, reduce climate impacts, and provide ecological restoration opportunities without undermining the state of offshore ecosystems, thereby positively contributing to ocean health (Hoegh-Guldberg et al. 2019b; Nash et al. 2020). This can be achieved through, for example, the use of innovative technologies for carbon drawdown and sequestration and for novel or more efficient resource use (Buck et al. 2017; Hoegh-Guldberg et al. 2019a; Bax et al. 2020b).

This paper represents the first known dedicated examination of the opportunities and challenges associated with Blue Economy developments within the offshore zone. While quantitative projections for economic and employment growth for the overall Blue Economy abound, at the time of writing, projections specific to the offshore waters are rare. To the best of our effort, we could only find trends inferred from more general discussions of the Blue Economy across all regions and jurisdictions, or descriptions of qualitative and aspirational trends, whose quantification is heavily conditioned on the development of supporting technology and future market trends. With projections hard to come by, planning may develop around assumptions, expectations and concerns and may tend towards supporting path dependency (the risk of missed opportunities due to the sequence of developments) along a business as usual trajectory.

This paper begins to address this gap by exploring a number of questions. First, we ask to what extent a business as usual development can achieve the Blue Economy promise of significant economic benefits while ensuring environmental protection and social justice. Since our analysis suggests that this is 
unlikely, next we ask what a realistic future characterized by socially equitable economic and environmental sustainability would look like. Finally, we ask how the future can be steered from the more likely business as usual to the more desirable, sustainable one. Our vision integrates ecological, economic, social, political and technological drivers and is capable of directing offshore activities towards a more sustainable future by accounting for both past lessons of unsustainable coastal and land developments (e.g. Caswell et al. 2020) and future technological possibilities. The more sustainable offshore Blue Economy vision we propose will help shape the direction of ocean developments over the course of the UN Decade of Ocean Science for Sustainable Development (2021-2030; UNESCO 2019). It is congruent with the UN Sustainable Development Goals (SDGs), which are globally accepted recommendations for future developments in areas as diverse as poverty, education and climate change (Nilsson et al. 2016).

\section{Methods}

Our interdisciplinary team comprised researchers across career stages and from different environmental and social disciplines. We collaborated over a series of workshops and meetings in 2018 and 2019 that were organised as part of the Future Seas project (https:// futureseas2030.org/). This project aimed at developing mobilising narratives across key challenges for the future of our ocean (one of which is developing the offshore Blue Economy) and involved more than 100 scientists. Working in such extended group allowed for inputs from Future Seas participants beyond those directly involved in this paper.

We followed the methods tested and agreed during the first Future Seas workshop and common to all challenges (Nash et al. forthcoming). We developed two plausible futures in 2030 for the offshore Blue Economy and defined a pathway to action. The first of these futures is the anticipated business as usual based on current trajectories (Plankque et al. 2019) and informed by published evidence. The second is an optimistic but technically achievable more sustainable future aligned (as much as possible) with SDGs and informed by existing and emerging knowledge. We used a predictive approach to develop the business as usual scenario and a normative approach to build the more sustainable scenario (Börjeson et al. 2006). A range of assumptions negotiated among Future Seas participants and common to all challenges constrain the futures. Example of these assumptions are that population and resource use will continue to increase to 2030, and that the globe is locked into climate change of at least $1.5^{\circ} \mathrm{C}$ by 2030 . A full list of assumptions can be found in Nash et al. (forthcoming).

Scenario development

As a first step towards scenarios development, we identified key drivers that society can influence and that will impact the offshore Blue Economy over the Decade for Ocean Science (by 2030; UNESCO 2019) (Table 1). To do so, we brainstormed drivers of change in six categories: political, economic, social, technological, legal, and environmental. Following brainstorming, we revised our detailed drivers and grouped them into broader categories. Last, we mapped these categorised drivers on a graph of lowto-high-influence versus low-to-high-impact axes, and we selected those that society can most influence and that are characterised by a high degree of impact on the offshore Blue Economy.

Once satisfied with our selection, we determined shifts in the intensity and direction of drivers that will lead to the different futures. This resulted in a table of key drivers and their behaviour in the context of the business as usual and the more sustainable future. This table became the starting point for developing the narrative around the alternative futures (Table 1). To guide the definition of the business as usual and the more sustainable future, we also looked to the SDGs. We identified which of the globally important goals the offshore Blue Economy has the greatest potential to influence (Fig. 2 and Table 1) and we discussed to what extent they might be achieved in each future (Table S1). We gave less consideration to SDGs that are more relevant to other papers of this special issue (e.g. Farmery et al. 2020 focusing on SDG Zero Hunger, Alexander et al. submitted to this species issue and considering equity as per SDG 10, and Trebilco et al. 2020 discussing climate actions).

We acknowledge that the evolution of the COVID19 pandemic is causing major changes to economies and socioecological systems at the global scale. It has changed growth rates and has seen calls for a redirection during recovery, thus potentially pulled 
Table 1 Business as usual versus our vision of a more sustainable offshore Blue Economy in 2030

\begin{tabular}{|c|c|c|c|}
\hline Driver & Business as usual & Sustainable future & SDGs \\
\hline \multirow[t]{3}{*}{ Governance } & $\begin{array}{l}\text { Unstructured approach to offshore } \\
\text { developments }\end{array}$ & $\begin{array}{l}\text { Structured approach to offshore } \\
\text { developments }\end{array}$ & 9,14 \\
\hline & Inadequate redistribution of benefits & Fair redistribution of benefits & $8,12,16$ \\
\hline & Ineffective environmental management & Effective environmental management & 14,17 \\
\hline \multirow{2}{*}{$\begin{array}{l}\text { Research \& } \\
\text { Innovation }\end{array}$} & Innovation largely within industry silos & Shared investments and technologies & $7,9,14,17$ \\
\hline & Hidden data and information & Transparent data and information & $9,14,17$ \\
\hline \multirow[t]{2}{*}{ Values of the Ocean } & Weak environmental consciousness & Greater environmental consciousness & 12,14 \\
\hline & Weak private sector engagement with SDGs & $\begin{array}{l}\text { Greater private sector engagement with } \\
\text { SDGs }\end{array}$ & $9,12,14$ \\
\hline \multirow[t]{2}{*}{ Partnership } & Geopolitical emphasis on expansion & Geopolitical emphasis on sustainability & 16,17 \\
\hline & Loss of collaboration & Global collaboration & 17 \\
\hline
\end{tabular}

The table shows key drivers of a growing Blue Economy that society can influence and that will determine how offshore developments evolve, as well as the Sustainable Development Goals (SDGs) that the offshore Blue Economy has the greatest potential to influence. See Table S1 for more details

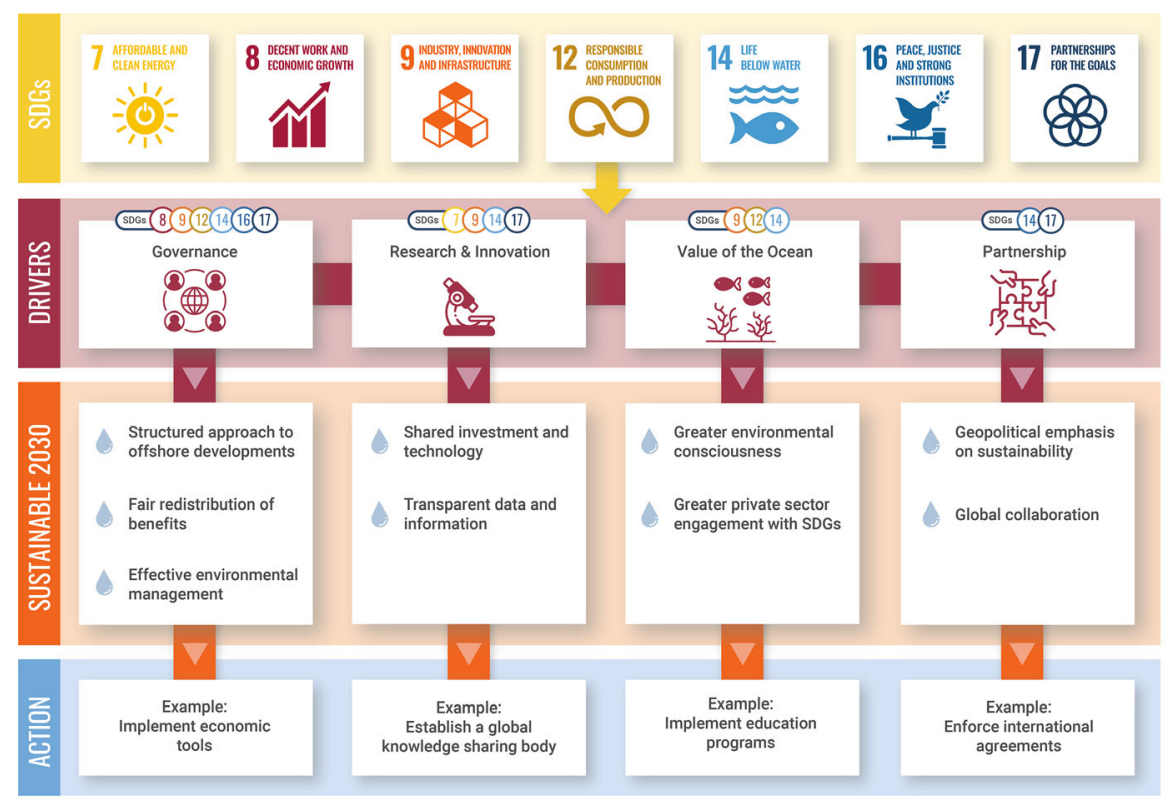

Fig. 2 Our vision of a more sustainable offshore Blue Economy in 2030. Each descriptor of the sustainable 2030 (e.g. structured approach to offshore developments) has the potential to contribute to the achievement of one or more Sustainable Development Goals (e.g. SDGs 9 and 14). This is conditional on shifts in the intensity and direction of the driver linking the descriptor with the SDG (e.g. Governance).

society away from the business as usual path as outlined here and based on evidence prior to the pandemic. Free from any defined trajectory, society has a choice to make. It can return to the business as
Examples of tangible actions that support society in moving towards the sustainable 2030 are provided (see Table S2 for more details on actions). The offshore Blue Economy also plays a key role in meeting SDG 2 (Zero Hunger), SDG 10 (Reduced Inequalities) and SDG 15 (Climate Actions), and we refer in the text to other papers of the Future Seas special issues for a thorough consideration of these topics

usual trajectory prior to COVID-19 in the next few years; or it can consider the current disruption to the global ocean, environment and society because of COVID-19 as an opportunity to switch to a different 
trajectory in the coming decade (as discussed in Pecl et al. submitted to this special issue). The sustainable future presented here is one option for such a shift.

Pathway towards a more sustainable future

We used a backcasting technique to identify tangible actions that support society in moving towards the more sustainable future. Backcasting is commonly used to define pathways that require knowledge of the end-point to determine the actions needed to reach that point (Robinson 1990). As a first step and guided by our vision of a more sustainable future, we brainstormed actions required to achieve this future and we identified who among the actors of the offshore Blue Economy (civil society, government, non-government and international organisations, industry, academia) should take each action. Next, we asked how long it would take for each action to be implemented and we placed each action on a 2021-2030 timeline, coinciding with the UN Decade of Ocean Science. Last, we identified the risks of taking actions. The aim of this last step was to promote a deep consideration of all aspects of an action (gains and losses), and to isolate actions that might lead to unintended outcomes and path dependency or that require additional precursors or enabling actions.

Both the process of scenario development and that of identification of tangible actions were iterative and involved repeated revisions of constituent steps and components (drivers, characteristics and descriptions of futures, and actions).

\section{The alternative futures}

We identify the following four drivers of a growing offshore Blue Economy that will determine how developments evolve (Fig. 2 and Table S1). Firstly, Governance will guide decision making over common marine resources (Haward and Vince 2008; Campbell et al. 2016; Haas et al. 2020). Secondly, Research and Innovation will influence the nature and scope of offshore developments and their ability to address global issues (e.g. pollution and climate change; Rockström et al. 2017; Vince and Hardesty 2017). Thirdly, (instrumental and intrinsic) Values of the Ocean will influence social preferences around offshore development (Jamieson 2008; Gee 2010;
Bidwell 2017). Finally, Partnerships between economic sectors and between nations, along with institutions regulating developments, will determine investment strategies and the degree of knowledge being shared (Bebbington et al. 2019; Bennett et al. 2019; Laffoley et al. 2019). These drivers, or facilitating mechanisms, interact with each other. For example, decision making around environmental sustainability could incentivise the development of new clean technologies and implement evidencebased co-management arrangements (Armitage et al. 2009).

As positive changes and interactions between these drivers enable sustainable development, the offshore Blue Economy has the potential to contribute to multiple SDGs (Hoegh-Guldberg et al. 2019a). It has the greatest potential to contribute to SDG 7 (Affordable and Clean Energy), SDG 8 (Decent Work and Economic Growth), SDG 9 (Industry, Innovation and Infrastructure), SDG 12 (Responsible Consumption and Production), SDG 14 (Life Below Water), SDG 16 (Peace, Justice and Strong Institutions) and SDG 17 (Partnership for the Goals) (see Fig. 2 and Table 1 for a description of the alternative futures in relation to drivers and SDGs; see Table S1 for more details). The offshore Blue Economy also plays a key role in meeting SDG 2 (Zero Hunger), SDG 10 (Reduced Inequalities) and SDG 15 (Climate Actions), but see Farmery et al. 2020, Trebilco et al. 2020 and Alexander et al. submitted to this special issue for a thorough consideration of these topics in the context of the Future Seas special issues.

\section{Business as usual}

In the business as usual future, the growth oriented economic model continues to emphasise profit and GDP growth, the commodification of nature, the dominance of private over public and cultural interests, and the prioritisation of the interests of current over future generations (Carmody 2012). Economic growth is centred in high-income, high-consumption countries. Low-income countries face many social and economic barriers in transitioning to sustainability, and this often results in unrestricted and unsustainable resource extraction (Jamieson 2008). Alternative economic models, such as well-being, degrowth, and the circular economy are attracting increasing recognition as being necessary to achieve the SDGs (Hadjimichael 
2018; Schroeder et al. 2019; Ertör and Hadjimichael 2020), but their implementation remains marginal. For instance, the circular economy, where excessive waste generation is avoided and unavoidable waste becomes a resource (Lacy and Rutqvist 2016), is selectively implemented in relation to plastic pollution and restricted aspects of food production (Table 1 and S1).

Offshore activities are corporatized and resource ownership highly concentrated. Companies are granted private or leasehold rights to access offshore resources under legal frameworks that silo development considerations. As such, opportunities to address cumulative effects are missed and ultimately conservation is undermined. Low effective corporate taxation and inadequate mechanisms for capturing and redistributing benefits mean that inequities persist, and wealth is further concentrated. At the same time, the growing trend of globally sustainable and responsible investments continues to develop (Global Sustainable Investment Alliance 2018). While these investments are effective and come to dominate markets in affluent nations, they remain mostly restricted to Australia, New Zealand, Canada, Europe, UK, Japan and the United States (Global Sustainable Investment Alliance 2018). Other high-income countries, such as Singapore, Israel, South Korea and South Africa may follow suit.

Declining inshore options drives technological innovation which advances the capacity to operate in offshore environments. While some locations undergo a pulse of development, economically viable offshore operations for emergent industries in other locations is slower than anticipated due to the need to work in a remote, harsh and poorly understood environment. This is mirrored more broadly in the slow progress made in developing sustainable solutions for offshore areas, which is (in part) driven by the tendency of society to look to offshore alternatives only when land based solutions reach breaking point. Slow progress is also due to our failure to gain knowledge and think strategically about cumulative and intergenerational impacts (Halpern et al. 2019). The lack of societal concern is because the offshore is 'out of sight and out of mind' and, generally, there is poor reflection upon the values of offshore areas (Heidenreich 2016).

Monitoring and reporting requirements are fragmented and inconsistent because it is often unclear what newer industries can deliver and regulatory incentives and enforcement thus lag behind development. While smaller sectors that are in an early development stage may see benefits in information sharing, their resource monitoring and reporting capacity is small. Larger sectors are less inclined to share data due to company ownership structures and concern over losing competitive advantage (Duchbrown and Mueller-langer 2017). For example, data collected during exploration to assess the economic potential of offshore resources are rarely made readily available or are only partially shared. This prevents full cataloguing of baseline ecological functions, delays policy and regulatory development and hampers the growth of sustainable ocean business which requires this information (Glover et al. 2018; Jones et al. 2019; UN Global Compact 2019).

Limited data transparency and knowledge sharing means that much research and innovation occurs in isolation (Duch-brown and Mueller-langer 2017). The benefits of innovation are concentrated in a small number of countries and profitable companies and investors. Deployment of offshore renewable energy, in particular offshore wind, continues to grow, with growth rates of nearly $30 \%$ per year between 2010 and 2018 (International Energy Agency 2019). This growth is predominantly seen in the UK, EU and China. However in other jurisdictions, despite significant available resource, growth of offshore wind is less rapid. Challenges surrounding the capacity of the grid to cater for large growth in offshore generation (Business Network for Offshore Wind, 2019) or a yet to be established supply chain (Poulsen and Lima 2017) are slowing development of the industry. This leads to a patchy uptake of offshore renewables and sub-optimal benefits in terms of decarbonisation efforts (International Energy Agency 2019).

The growing cost of deteriorating ocean health, such as the cost of plastic pollution to the tourism industry (Krelling et al. 2017), encourages greater engagement with sustainability. Other efforts to reduce environmental impact of offshore industries are encouraged by stock market related expectations, Corporate Social Responsibility reporting (Gjølberg 2009; Steurer 2010; Landon-Lane 2018), and the industry's drive to attain Social License to Operate (Voyer and van Leeuwen 2019). However, quick fixes and isolated approaches result in a sizeable number of these efforts being ineffective or tokenistic (Golden et al. 2017). While international organisations look to take spatial management beyond simply "open" and 
"closed" areas through recognition of Other Effective Area-based Conservation Measures (OCEMs; e.g. Dudley et al. 2018), the divide between affluent nations and emerging economies in the capacity to enforce zoning is evident. Moreover, politically motivated simplification of environmental regulatory constraints at national level sees sophisticated multiple use zoning degrade to 'paper parks' in some nations. In other nations, a policy vacuum sees slow and haphazard regulatory action around developments of new offshore industries. These patterns are difficult to reverse and the resulting lack of regulatory policies factoring in the cost of environmentally damaging behaviours leads to industry continuing to use the environment as a free resource and to cynicism that the offshore Blue Economy is little more than 'blue washing' (Voyer and van Leeuwen 2019).

The spatial management and policy environment means offshore waters are often in effect divided into areas for production and extraction by individual sectors, and areas for conservation and protection (O'Leary et al. 2016). With a few exceptions, the spatial divisions mean that potential opportunities for co-location of industries or other bio-design inspired synergies are lost, and that the assessment of cumulative effects is compromised. Minimal investment in monitoring that is useful at a systematic scale and constrained regulatory budgets further hamper the assessment and management of impacts, leaving marine ecosystems exposed to significant risk of degradation (Ward et al. submitted to this special issue). These limitations play out in different ways for different sectors. For seabed mining, some countries uphold moratoria in their own EEZs, as they do now (e.g. New Zealand and Namibia; Levin et al. 2016; Ellis et al. 2017). Others undertake explorative mining with few provisions for rehabilitation of vulnerable marine ecosystems (Van Dover et al. 2014; Miller et al. 2018).

The value of mineral resources coupled with increasing on-land scarcity as mineral exporters retain production for domestic use sees a race to claim resource rich deposits. Countries claim Extended Continental Shelf (ECS) and expand their territorial right (EEZs) and maritime power to ensure continued access to offshore resources (Fig. 1; Tian et al. 2019; Jouffray et al. 2020). Potential for conflicts is high, particularly where resources extraction is lucrative or control over resources is strategic (Spijkers et al. 2018;
Jouffray et al. 2020). This includes areas where jurisdictions are shared or under multiple competing governance structures (O'Higgins et al. 2019; Schatz 2019; Barnes and Rosello 2020), or where there is an asymmetric power distribution between countries (Choi 2017). Global naval defence spending continues to rise for two seemingly separate reasons: expansion of national political agendas and economic interests; and provision of humanitarian assistance and disaster relief. Naval activities are facilitated by artificial islands and deep-water refuelling platforms, which slowly become available to the expanding civilian offshore Blue Economy.

Without firm motivation (whether market, regulatory or societal) there is a significant risk that developments are characterised by competition and asymmetric power relations. At present the Blue Economy has great political capital and legitimacy and it has brought together diverse sets of actors from across the public, private and non-government sectors (Winder and Le Heron 2017). However, this political capital could be damaged if there is no balance between offshore development, fair redistribution of benefits and environmental protection. If expectations are not met, the public will become disenfranchised with offshore Blue Economy outcomes and this could undo any gains and compromise the offshore sector's future.

\section{More sustainable future}

The more sustainable future avoids alienation of the public as the offshore Blue Economy is characterised by an intentional shift toward sustainability and equity. First, more thoughtfully balanced production, where managed growth of some sectors in balanced against de-growth of other sectors, means that the offshore economy contributes to the achievement of multiple SDGs. It ensures sustainable use of finite resources and helps reduce the risk of overshooting planetary boundaries to do with pollution, climate change and biosphere integrity (Nash et al. 2017). Second, growth of the circular economy and a reduction in consumption in high-income countries, which instead redirect their product to meet increased demand in low-income countries, help to minimise over-exploitation of raw resources and address rising global inequities. 
Offshore activity requires considerable research and development to overcome engineering and operational challenges and mitigate environmental impacts (Bailey et al. 2014; Kaldellis et al. 2016; Zanuttigh et al. 2016). A two-stage adaptive-management and precautionary principle inspired process is implemented to ensure a structured approach to offshore expansion (towards SDGs 9 and 14; Fig. 2 and table S1).

During the first stage (to 2030), government, industry, and academia collaborate to understand the impacts and implications of offshore developments (Zanuttigh et al. 2016). They design monitoring programs that support developments, provide sufficient information to inform regulatory bodies, and are affordable for emerging industries. This collaboration builds on decades of work on shared ocean observation systems (e.g. Global Ocean Observing System), development of marine spatial planning (Dunstan et al. 2016; Jones et al. 2016; Santos et al. 2020) and integrated assessment methods (Korpinen and Andersen 2016). It benefits from offshore platform investments and research and developement in Europe, US, China and Australia during the 2010s-2020s (e.g. the ENTROPI, OPEC, TROPOS and MUSICA projects). A proactive focus on cumulative effects and empirical testing of production and infrastructure technologies helps determine economic viability, social acceptability, regulatory suitability and environmental impacts (Durden et al. 2018).

During the second stage (2030 to 2040), pilot projects are evaluated to determine if and how licences for commercial developments should be issued, continued or expanded. The assessment is based on data from monitoring programs that are administered under protocols building off the FAIR data principles (Findable, Accessible, Interoperable, Reusable; Wilkinson et al. 2016). It considers trigger points for management intervention that are conservative and acknowledge uncertainty (Copping et al. 2016). While pilot projects mean a precautionary approach is taken, the potential for path dependence is minimised by casting a wide net for different possible technologies and development types.

Governments ensure equitable use of offshore resources (Bennett et al. 2019) with developments predicated on need and sited for maximum positive and synergistic outcomes (contributing to SDGs 8, 12, and 16). Developments are informed by transparent and strategic planning processes that include largescale marine spatial planning and systematic ecological and socioeconomic assessments such as those being developed for multi-use offshore platforms and based on social acceptance, social cost-benefit and multi-criteria decision analyses (Chen et al. 2014). In the short term, this means government incentivises research collaboration, invests into major infrastructure and capacity building, and encourages private sector investment. Over time, with adequate policies and mechanisms in place for equitable benefits sharing (Cisneros-Montemayor et al. 2019; Bateman and Mace 2020), the private sector may adopt the operating standards of government enterprises. Monitoring of developments and lease and licencing arrangements is through national and international institutions, and government regularly reviews and updates the sectoral operating requirements and fee structure. Fees are also used to capture economic rents that can be used to relieve poverty, improve health and well-being, and education (Lehmann et al. 2018).

Greater environmental consciousness, at both the individual and societal level, is reflected in consumer choices, planning, and other governance processes. Demand for environmentally friendly operations and products thus increases (contributing to SDGs 12 and 14) (e.g. Lim et al. 2018; Hilger et al. 2019). Some jurisdictions apply economic penalties to marine products that are not produced sustainably, while in other locations societal norms see demand for those products decreasing. At a deeper level, there is a growing recognition that the instrumental values of the ocean are at risk if environmental values are not maintained, and that societal costs are associated with environmental degradation. Technological innovations allow for informed personal choices on a dayto-day basis and facilitate the engagement with participatory processes. This drives a shift to more actively maintaining environmental values, recognising that a healthy and prosperous society is supported by healthy ecosystems (Nash et al. 2020).

Social and environmental responsibility drives more cost effective private sector engagement with SDGs and sustainability (in particular SDG 9, 12 and 14). Shareholder dividends account for environmental externalities which drives competition in the private sector to address sustainability concerns. Standard auditing practices require businesses to explicitly show externalities and sustainability accounting in 
annual reporting. Their contribution is measured against wellbeing and environmental stewardship (not just GDP). Investors increasingly look to these credentials to choose investment options (Global Sustainable Investment Alliance 2018; UN Global Compact 2019). By 2030 ethical and sustainable investments are standard practice in more affluent nations and dominate the investment market globally. Systems of national environmental accounts are integrated into political decision making alongside economic forecasts, and regularly include non-monetary and indirect ecosystem flows and function (Bateman and Mace 2020).

Offshore industry is encouraged to collaborate on, and share investment in, research and innovation and infrastructure (contributing to SDGs 7, 9, 14 and 17). Collaboration allows for faster innovation and delivers efficient technology that ensures real-time monitoring and minimises ecological impact for multi-use offshore platforms (Zanuttigh et al. 2016) without compromising the functionality of the infrastructure. These innovations include bio-design of physical platforms and the adoption of advanced composite materials that use chemical and nano-scale properties to allow or inhibit biofouling organisms. Innovation also aims for zero waste generation and carbon neutral (or even negative) footprints (Rockström et al. 2017) and provides support for regenerative practices, such as waste removal or habitat restoration in areas impacted by past damaging activities (Duarte et al. 2020). Increased production and uptake of offshore renewables, innovation in energy storage systems, and co-location of renewable production with other sectors (Rockström et al. 2017) achieves decarbonisation (see also Trebilco et al. 2020). By 2030 offshore aquaculture is a major carbon sequestration industry (Buck et al. 2017; Sondak et al. 2017) and source of bioenergy (Roesijadi et al. 2008).

High resolution scientific data are widely available and shared across sectors and countries (contributing to SDGs 9, 14 and 17). This is consistent with the UN Ocean Compact guidelines for growing sustainable ocean business which stress the need for industry to actively support ocean mapping initiatives and to share existing ocean data (UN Global Compact 2019). The Global Ocean Observing System provides a platform where ocean data can be shared and integrated. This platform comes at a cost, estimated to be roughly from USD 500 million to 1 billion per year (Claudet et al. 2020), but the benefits are crosssectoral. Efficient information sharing and cooperation across government, society, industry, and academia lead to agreed and evidence-based measures for marine environmental protection, speed up innovation, and encourage learning (Stuiver et al. 2016; Winther et al. 2020). Information sharing also reduces the individual costs of assessments and planning processes, and accelerates action and sustainable solutions. For example, estimates on the environmental cost of activities become available as more companies report their performance on carbon and plastic management (UNEP 2014; Beaumont et al. 2019). They show a drop in global marine environmental degradation costs as a direct result of a reduction in pressure on inshore waters and a structured and sustainable approach to moving activities offshore.

Cooperation between international institutions and governments helps shift the geopolitical emphasis to sustainable use of shared offshore resources (towards SDG 16). Naval military expenditure slows after naval modernisation by the world's major naval powers. The tension that both motivated and resulted from the modernisation reduces over time as geopolitical processes increasingly support conflict resolution and shared management. Capital investments by powerful nations focus on a small number of hightech mobile platforms that also support data streams for monitoring, reporting and compliance around offshore activities and have the potential to benefit humanitarian relief efforts. For example, mobile platforms may help establish secure and reliable communication networks in disaster zones, or act as offshore rescue and aid stations.

Global collaborations are fostered by the shared need for technological innovation, integrated monitoring, and recognition that offshore developments can address multiple SDGs (in line with SDG 17). Cooperation and knowledge sharing between landbased, coastal and offshore industries leads to a more accurate assessment of the cumulative impacts arising from the interaction between land and marine processes and encourages effective governance structures (Boschetti et al. 2020). Societal expectations around the development of new opportunities, sustainability, and equity are met. People are proud to be a part of this future. 
Pathway towards a more sustainable offshore Blue Economy

Required changes

Achieving our vision of a more sustainable future in 2030 will require four important changes. The first is a shift in the expression of societal values towards sustainable consumption and production, and environmental justice and consciousness (e.g. shared costs and benefits of ocean use across uses, nations and generations). The Bruntland definition of sustainable development (1987) captures the generational dimension of this, where "sustainable development is development that meets the needs of the present without compromising the ability of future generations to meet their own needs". But this definition can be paraphrased to capture also the current user and nation dimensions, where sustainable development is development that meets our own needs without compromising the needs of other users and nations. This involves working with communities to understand how different values may compete or interact and what may be preventing sustainable or equitable actions.

The second change is that the scale and allocation of funding to offshore Blue Economy activities are appropriate and ensure long-term sustainable and equitable financing. The third change is that information sharing between industries and across nations is enhanced and the focus shifts from competition to cooperation. The fourth change is that international legal and institutional mechanisms are implemented for ethical sharing of benefits, sustainable use and conflict resolution (see also Smith et al. 2020). This also means that minority and often marginalised groups, such as Indigenous and Traditional Peoples, are included in offshore Blue Economy planning processes and contribute knowledge on sustainable practices and ways of life, in line with international instruments (e.g. UN Declaration on the Rights of Indigenous Peoples) (Fischer et al. 2020).

In the next sections we discuss specific actions needed to achieve the four required changes (Fig. 3). Actions are numbered and numbers refer to Table S2, where more details on each action and its relation to drivers, SDGs and the sustainable future are given.

Some of the actions we propose are applicable across different challenges and systems, but they are particularly relevant in achieving a sustainable offshore Blue Economy. Historical and current trajectories for land and coastal systems show that often these actions have not been proactively undertaken to the extent needed (e.g. Caswell et al. 2020). This has resulted in over-industrialisation and depletion, which are conditions difficult to reverse. In contrast, the offshore Blue Economy is emerging. It offers the rare opportunity to drive development and conservation from implementation rather than having to redress past mistakes, and thus to design a future that encompass innovative concepts (e.g. SDGs, circular and balanced economies). The offshore Blue Economy also poses new challenges. Offshore waters are a remote and unknown space, thus actions applicable across systems will need to be tailored to new needs and to account for a general lack of knowledge.

\section{Shift in the expression of societal values}

To shift societal values, national governments, the education sector, NGOs and industry need to work collaboratively to implement school and societal awareness and education programs (Fig. 3) (Kelly et al. forthcoming; Claudet et al. 2020). These programs should be combined with immersive experiences that include, for example, participation in hands-on workshops and game-based training for enhanced engagement and learning (Dede 2009). They shift the public perception of offshore developments from being a distant possibility to being part of their future as custodians of the planet. They inform the public that offshore development is already happening, that offshore platforms are becoming reality, and that now is the time to steer industries in a desired direction. They demonstrate that the instrumental values of offshore areas are not indefinitely resilient and that 'out of sight' must not be 'out of mind' (Fig. 3; action No. 30 and 34 in Table S2) (Jamieson 2008).

Academia needs to increase understanding of the environment-economy-society interdependencies and sustainable actions, as this information is key in developing education programs (action 31 and 40). Education programs should focus on interdisciplinarity to allow integration of different knowledge for the diverse components of the marine environment. The current tendency to bias natural science should be avoided and true integration of social sciences should be the ultimate aim (Alexander et al. 2019, Fortunato et al. 2018). Education programs should also promote environmental justice, reduction of resource consumption and sustainable choices, and in turn create realistic 


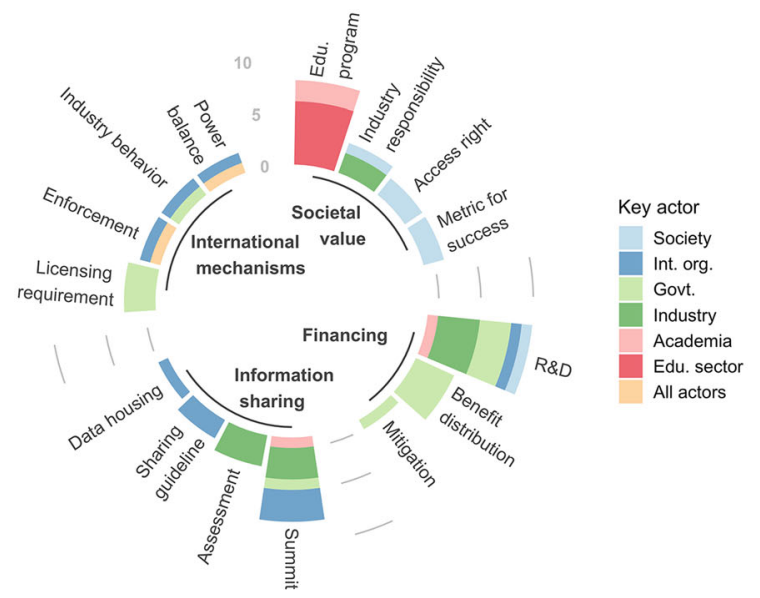

Fig. 3 Summaries of actions to achieve a more sustainable offshore Blue Economy in 2030, based on the accomplishment of four key changes: (1) a shift in the expression of societal values towards sustainable consumption and production, and environmental justice; (2) the implementation of economic tools to ensure sustainable and equitable financing; (3) the enhancement of information sharing between industries and across nations; and (4) the implementation of international legal and

social expectations about emerging offshore industries (actions 32, 36, 38 and 39) (Jamieson 2008; Ripple et al. 2019). Media that provides room for responsible reflection and respectful dialog can help facilitate this process.

A society that is supported to think critically will call for reporting and regulatory requirements that consider environmental externalities and contribution to wellbeing (actions 6 and 41). It will also raise the standards of industry's Social License to Operate (SLO), and thus demand for greater industry transparency, social responsibility and environmental stewardship. Industry, in turn, needs to increase the focus on achieving SLO and delivering on transparency, responsibility and environmental goals (action 41). It needs to go beyond tokenism and engage with society in a collaborative and genuine manner (actions 33, 37, and 41) (Harvey and Bice 2014; Ripple et al. 2019; Voyer and van Leeuwen 2019). Innovative and responsible industries need to lead by example. For instance, innovative offshore aquaculture industries should explore Integrated MultiTrophic Aquaculture (IMTA) and ecosystem aquaculture (Chopin 2013), given the shortcomings of many land based monocultural systems. Investors need to continue to grow ethical and responsible investments and better account for environmental impacts as part of their risk management strategies.

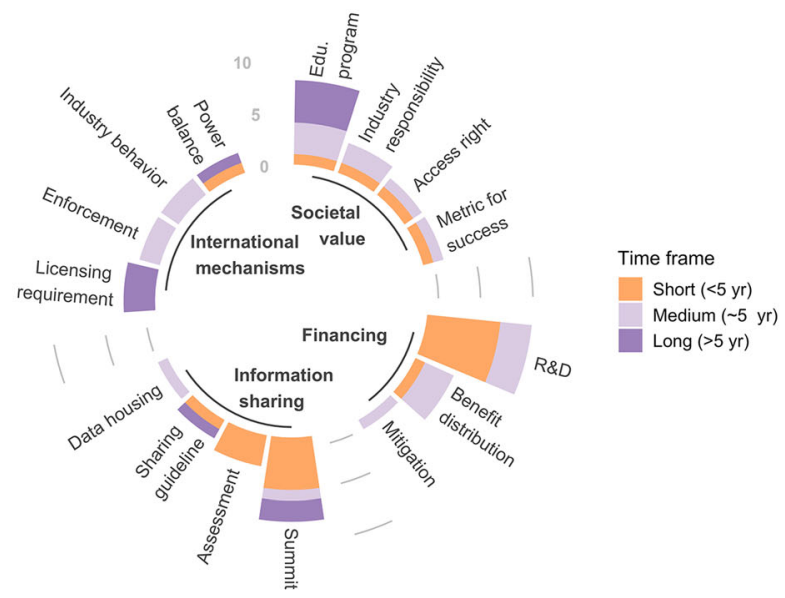

institutional mechanisms for ethical sharing of benefits, sustainable use and conflict resolution. Actions are grouped into topics (e.g. education programs), and the 0-10 scale indicates the number of action for each topic. The key actor in charge of each action and the action time frame is provided (see Table S2 for more details on actions). int. org. = international organisation; govt. = government; edu. $=$ education

More generally, society, international organisations, and national governments need to reconsider legislative and policy goals and metrics, moving towards reporting a broader set of environmental and wellbeing goals and indicators (action 6) (Bennett et al. 2019). As a first step, no human (or country) should be forced to put short term interests (e.g. provide for family basic needs) ahead of long term interests (e.g. maintain the instrumental value of the ocean; Hardin 1968) (action 35). Social, institutional and political changes need to stem from collaboration between society, national governments, and international organisations to determine equitable access rights and benefit redistribution from offshore activities both within and between nations (action 3, 4 and 5) (Bennett et al. 2019). In such context, criteria to determine beneficiaries may include, for example, the community's dependence on the ocean, distance from the ocean and cultural connection to the ocean. This is noting that any action dealing with mechanisms to support equity or with ways of achieving sustainability by adopting alternative economic models sits centrally within broader discussions, for example on environmental justice, that society has to have. Rapidly progressing these discussions in the next decade is fundamental and achievable, but reaching agreements may require longer times (see also 'risks and path dependency of actions'). 
Meanwhile, concrete actions towards more equitable Blue Economy outcomes are possible. For instance, government, academia and industry need to ensure that technological advances not only address engineering and operational solutions to offshore developments but also environmental and equity solutions. Such solutions could include innovative aquaculture and energy production systems and legislative requirements that enable smaller scale and less developed countries access to offshore developments (action 5; Stead 2019).

\section{Sustainable and equitable financing}

Following deliberations, mechanisms that improve and ensure long-term sustainable and equitable financing need to be implemented (action 1) (Thiele and Gerber 2017; Jouffray et al. 2019; Laffoley et al. 2019). Financial mechanisms to capture the net social benefit from developments should be progressive, with greater demands on high return and high-impact sectors (action 2). Part of the funds generated from these mechanisms needs to be redirected to ensure redistribution of benefits beyond national boundaries (actions 3 and 4). This is of particular importance when moving from an EEZ and country-centric focus to globally redistributing benefits from the use of the high seas (and the Area). The remaining funds should be allocated to fair redistribution of benefits within nations (actions 1, 2, 4 and 5), research and development that support monitoring and clean, efficient, multi-sectoral offshore uses (e.g. platforms; actions 8 , 10, 28 and 51), and environmental impact mitigation and rehabilitation (actions 15 and 18) (Bebbington et al. 2019; Ripple et al. 2019; Duarte et al. 2020).

Innovative financing mechanisms and supplementary sources of funds also need to be explored and adopted to speed up technological innovation and uptake (actions 19, 23-25) (Hemer et al. 2019; Laffoley et al. 2019; Wabnitz \& Blasiak 2019; Claudet et al. 2020). Innovative financing mechanisms may include blue bond and blended finances (Thiele and Gerber 2017; Fritsch 2020). Supplementary sources of funds may include stakeholder donations and private fundraising, crowdfunding for offshore investment and installations, and contributions from large private organisations, such as internet portals investing in ocean monitoring (e.g. Google Ocean). For example, voluntary and regulatory financing frameworks that support the restoration of coastal blue carbon ecosystems, such as mangroves and seagrasses (Vanderklift et al. 2019), can be extended to finance large-scale aquaculture plants that act as major carbon sequestration sites (and that generate carbon credit). The noncarbon co-benefits associated with offshore aquaculture plants, including food and bioenergy production, provide opportunity to attract investors and generate additional financial support (Vanderklift et al. 2019). This opportunity is maximized when the aquaculture industry is efficiently linked to other industries, within an offshore platform context. As proposed for coastal systems, actions to generate the appropriate type and scale of financial investments include an analysis of the motivation of potential investors, the development of demonstration projects and linked risk management strategies, and a customization of the final product to meet the local environmental, socioeconomic, and regulatory context (Vanderklift et al. 2019).

While the current decade will see the start of offshore development with initial emphasis primarily on food and energy systems, larger multi-use developments including offshore ports, housing and transportation hubs are being touted. However, the need to structure new growth developments that are both sustainable and within planetary boundaries (Steffen et al. 2015; Nash et al. 2017) has led to a rethinking of global economies (e.g. Kallis et al. 2012). The offshore Blue Economy has the potential to develop and embrace emerging societal concerns of overexploitation and inefficient use of natural resources. For example, offshore leases can be offered to operators that buy out inshore food or energy quotas and thus enhance the restoration of coastal systems. Likewise, they could be offered to operators that recycle high percentages of materials throughout the production and supply chains of their businesses.

\section{Information sharing}

To foster information sharing, international organisations, national governments, industry, and academia need to collaborate (Laffoley et al. 2019; Pearlman et al. 2019; Claudet et al. 2020), and maximise transferability through data standards (Fig. 3). Shared information should be used to develop robust planning processes and Environmental Impact Assessments (action 27) (UNEP \& GEF-STAP 2014; Durden et al. 2018). Data collection and sharing may require 
expensive technologies, such as artificial intelligence driven autonomous underwater vehicles and real time data visualisation dashboards (action 10) (Mayer 2006; Yoerger et al. 2007). Shared data should incorporate life-cycle assessment of infrastructure including the shared benefit (or impact) of co-location, the logistical and operational footprint, and information about biodiversity impacts of removal versus repurposing (action 17). Biodiversity consideration should include biosecurity aspects, such as new infrastructures acting as an invasion stepping stone or as protected habitat for sedentary species (action 17). Sharing information should allow industry planners to make rapid and well-informed decisions and thus streamline assessment and approval processes (action 26) (Pearlman et al. 2019).

National governments and international organisations need to centrally house all publicly funded data and make it easily accessible (action 29). The costs of the data warehouse process for businesses should be recognised as legitimate business costs (i.e. deductibles) and partly covered by small purchases, where data users can access some data and functionality freely but must pay for additional aspects (action 29). The scope of international organisations that collect data on ocean economic activities, such as those for deep sea mining and transport and trade (e.g. the International Seabed Authority, the World Trade Organisation and the International Maritime Organisation), needs to be expanded to include all sectors and countries. The aim is to facilitate and regulate collection and integration of this data and, most importantly, to encourage knowledge exchange which supports integrated ocean management and innovation (action 20; Winther et al. 2020). There is a need to establish clear guidelines on how to achieve knowledge exchange while protecting Intellectual Property that are enforced by national regulators (action 21; UN Global Compact 2019; Claudet et al. 2020).

To foster collaborations across countries and industries, international organisations, national governments, and academia need to run national and international summits and support clusters of collaborators (e.g. the High Level Panel for a Sustainable Ocean Economy, and the World Ocean Council) (actions 44, 45, 47, 48). Options for web-based summits should be encouraged and remote participation seen as an opportunity for increasing or diversifying attendance while reducing carbon contribution.
This has already been witnessed in many international meetings held during COVID-19 restrictions, where attendees who would normally be blocked by finances, disabilities or local commitments could attend. The opportunities for collaboration will allow players to share their lessons learned, and in particular between established and emerging sectors (Hemer et al. 2018). They will provide a way to find hidden opportunities and financial incentives for sectors to co-develop small and large-scale offshore infrastructure, such as major platforms or energy arrays (e.g. by-products of one sector may solve the needs of another sector)(actions 9, 49 and 51-53).

The commercial focus throughout the 2010s has been on large infrastructure, with little input from Indigenous and Traditional Peoples. The introduction of respect, recognition and understanding of Indigenous ways of life within the offshore Blue Economy could see a multitude of alternative options emerge (Claudet et al. 2020; Vincent et al. 2020), with the potential for blending of modern manufacturing technology with traditional practices (Fischer et al. 2020).

\section{International legal and institutional mechanisms}

International organisations, national governments, society, and academia need to improve, ratify, and enforce existing international agreements that promote ethical sharing of benefits and shift the geopolitical emphasis to sustainable use (e.g. the Convention on Biological Diversity; UN General Assembly 1982; Bennett et al. 2019; Laffoley et al. 2019) (13 and 42). Such improved agreements should 1) include resource sharing contracts between countries; 2) set international standards around industry behaviour (e.g. sustainable food and green transport certifications; action 12 and 50); and 3) set stringent requirements on licencing arrangements for exploration and their enforcement in EEZs (action 7). Requirements should include regulations on financing mechanisms, reflect uncertainty with respect to Environmental Risk Assessments, promote economic activities with a focus on mitigation and restoration (Duarte et al. 2020), low or zero carbon emissions and energy self-sufficiency or excess production (actions 11, 15 and 16). Achieving this collaborative outcome demands high-level coordination among institutions and international agreements. 
It also requires a careful consideration of power imbalances that might influence negotiations between countries and sectors (Bateman \& Mace 2020; Vincent et al. 2020). International and regulatory bodies for conflict resolution, such as the International Court of Justice, need to be bound by rules designated to mitigate these imbalances (action 43). Power dynamics need to be considered at multiple levels and, when possible, before they result in conflicts that require legal resolution. This includes, for example, regulating power dynamics that emerge during meetings involving several sectors with contrasting interests (e.g. Bateman and Mace 2020). Small scale examples of conflict resolution and mediation techniques are readily available, but novel approaches such as a different design of meetings that, for instance, dismantle hierarchical set ups (Colvin et al. 2016) may provide useful starting points for new approaches (action 46).

Key actors and time frame of actions

Achieving our vision of a more sustainable future in 2030 is a collaborative and interdisciplinary effort that see all actors playing an important part in success. It also requires a coordinated and prompt start on actions that will need to be revised and continued until or beyond 2030. There are however actors that will be more influential in implementing a specific set of actions and actions that can be implemented before others (Fig. 3). For instance, most of the actions that we propose to foster information sharing can be implemented within a short to medium time frame (before 2025), and industry and international organisations will play an important role in their achievement. An example of these actions is to increase collaboration between established and emerging sectors of the offshore Blue Economy and between these sectors and the land and coastal ones so that lessons learned can be transferred (action 48).

Similarly, most actions ensuring sustainable and equitable financing can be implemented with a medium time frame (around 2025), with national governments, industry and other investors being the key actors. Examples are to enhance economic tools on high-impact and high-income sectors and to increase financing mechanisms that support activities with clear environmental and social benefits (actions 2 and 23). Instead, actions that promote a shift in the expression of societal values can be achieved at different times during the Ocean Decade (2021-2030) but mostly fall within the medium to long term category (after 2025). Civil society and the broad education sector enable this change. Last, actions dealing with international legal and institutional mechanisms will require longer time frames (by 2030) and their realization will mostly depend on national governments and international organisations. These actions include, for example, to grant licences for economic activities in offshore waters based on equity and sustainability criteria (e.g. zero waste generation and carbon neutral footprints; Buck et al. 2017; Rockström et al. 2017).

Risk and path dependency of actions

Business as usual is not the worst possible future. It is a future that sees improvements compared to the present situation, but that does not live up to the greater potential of the more sustainable alternative. There are risks involved in choosing a more sustainable future over business as usual. Consideration of these risks should assess whether the additional effort required in taking an action is justified; if it is a significant cost, does it lead to substantial or only marginal gain? Our pathway towards a more sustainable future does not guarantee the outcome because of potential risks along the way, but considering these risks substantially increases potential for improved outcomes.

Negotiations and deliberations on the allocation of rights and redistribution of benefits from offshore activities may lead to political polarization and conflicts (Nie 2003). Some societies may want to defend their existing rights and refuse to accept what they perceive as an unjust redistribution of rights and benefits (Jamieson 2008). Political conflicts over offshore resources may intensify once their true value becomes apparent. Countries may refuse to respect international agreements, and international bodies that are responsible for regulation may instead foster collusion. Discussions on the allocation of rights and redistribution of benefits from offshore activities may continue for decades.

Authorities may fail to agree on reporting standards or to properly enforce international and national regulations around financing mechanisms, data, and knowledge sharing. This may undermine the intent and outcome of any new regulation (Galaz et al. 2018). 
For example, the lack of transparency in the taxation process and the use of tax havens may lead to consistent losses in tax revenues, and in turn weaken social and environmental investments (Galaz et al. 2018). Similarly, countries and industries may provide poor quality data to protect commercial interests or for political reasons. Data confidentiality (or even formats) may continue to be a barrier to data sharing and management. This may hamper collaboration and development.

International requirements on exploration and initial licencing phases to ensure a structured approach to development may instead lead to inertia, disagreement over intent and regulatory capture (e.g. through disproportionate influence of lobby groups on regulatory outcomes; Dal Bó 2006). International requirements may inadvertently reduce investment and innovation and slow uptake of technologies and research and development, ultimately resulting in path dependency and a lack of critical mass essential for involvement.

All of these represent real risks in achieving a sustainable future. The choice society faces is to take actions involving known risks towards an aspirational future or to continue down a route of least resistance that will lead to a less desirable future (business as usual).

\section{Conclusion}

Offshore waters are instrumentally valuable to humans but not indefinitely resilient. Their future will likely play out at the interface between current exploitation trends and societal aspirations. Aiming to overcome the inertia of an undesired business as usual development, we took the UN Sustainable Development Goals and the values they underscore as statements of societal aspirations and identified the actions that may lead to their realisation. The sustainable and equitable offshore Blue Economy we envisaged is achievable, conditional on changes in our governance structures, the way we collaborate, and the extent to which societal values change and are expressed through behaviours. This includes a reconsideration of the purpose of economic activities, which accounts for the need of a growing population, to address rising global inequities and to recognise the essential role of nature for human well-being.
The recent evolution of the COVID-19 global pandemic has further increased uncertainty around future trajectories (Baldwin and Weder di Mauro 2020). We do not yet have the evidence to examine the consequences of such disruption on the offshore Blue Economy, but we can anticipate that some of the aspects discussed in this paper are likely to be affected. Importantly, the global crisis has highlighted inequities and brittleness in some of the flows of the current economic model (Baldwin and Weder di Mauro 2020). Sudden and substantial changes in production and consumption have been disruptive for some ocean sectors (e.g. transport and tourism; Northrop et al. 2020). This disruption has however, provided a global opportunity to discuss alternative economic models that would lead to a more equitable and sustainable direction (Cohen 2020).

The relevant question now is what a post-pandemic future should look like (Northrop et al. 2020). For the offshore, new opportunities may rise through prioritising recovery of some sectors over others, building on shifts in production that have occurred, or leveraging off competition in the financial marketplace (Northrop et al. 2020; Chiaramonti and Maniatis 2020). For example, instability following the COVID19 outbreak has exacerbated an oil price war between suppliers (Chiaramonti and Maniatis 2020). Oil prices dropped below the threshold of profitability in MarchMay 2020. While changes in production will help redress this, they may also incentivise investments into the (offshore) renewable energy sector which currently promises more attractive financial returns (Chiaramonti and Maniatis 2020).

At the close of 2019, it could be readily argued that inertia was likely to lock the offshore Blue Economy into a business as usual future. We could act to make a more sustainable future as palatable as possible, but redirecting the global economic model was highly unlikely. The kind of actions needed had been called for before, for decades, and while progress had been made it was incremental rather than transformative. Midway through 2020 the position is very different, COVID-19 has shaken the globe (e.g. Baldwin and Weder di Mauro 2020; Northrop et al. 2020). The offshore Blue Economy does not automatically need to return to the old business as usual path, it could now more easily redirect to a sustainable future. 
Acknowledgment This paper is part of the 'Future Seas' initiative (www.FutureSeas2030.org), hosted by the Centre for Marine Socioecology at the University of Tasmania. This initiative delivers a series of journal articles addressing key challenges for the UN International Decade of Ocean Science for Sustainable Development 2021-2030. The general concepts and methods applied in many of these papers were developed in large collaborative workshops involving more participants than listed as co-authors here, and we are grateful for their collective input. Funding for Future Seas was provided by the Centre for Marine Socioecology, the Institute for Marine and Antarctic Science, MENZIES and the College of Arts, Law and Education, the College of Science and Engineering at the University of Tasmania, and Snowchange from Finland. We acknowledge support from a Research Enhancement Program grant from the DVCR Office at the University of Tasmania. Thank you to Mibu Fischer, Kimberly Maxwell and Philippa McCormack for providing an internal project review of an earlier draft and to 3 anonymous reviewers for challenging us to be clear about the vision and consequently improving the manuscript. Thank you to Derek Fulton for contributing to the figures. We acknowledge and pay respect to the traditional owners and custodians of sea country all around the world, and recognise their collective wisdom and knowledge of our ocean and coasts.

Funding This paper is part of the 'Future Seas' initiative. Funding for Future Seas was provided by the Centre for Marine Socioecology, IMAS, MENZIES and the College of Arts, Law and Education, the College of Science and Engineering at UTAS, and Snowchange from Finland. We acknowledge support from a Research Enhancement Program grant from the DVCR Office at UTAS.

\section{References}

Alexander KA, Hobday AJ, Cvitanovic C et al (2019) Progress in integrating natural and social science in marine ecosystem-based management research. Mar Freshwater Res 70(1):71-83

Appiott J, Dhanju A, Cicin-Sain B (2014) Encouraging renewable energy in the offshore environment. Ocean Coast Manag. https://doi.org/10.1016/j.ocecoaman.2013.11.001

Armitage DR, Plummer R, Berkes F et al (2009) Adaptive comanagement for social-ecological complexity. Front Ecol Environ 7:95-102

UN General Assembly (1982) Convention on the Law of the Sea. https://www.refworld.org/docid/3dd8fd1b4.html. Accessed 18 Feb 2020

Bailey H, Brookes KL, Thompson PM (2014) Assessing environmental impacts of offshore wind farms: lessons learned and recommendations for the future. Aquat Biosyst 10:8

Baldwin R, Weder di Mauro B (2020) Economics in the time of COVID-19. Ocean Coast Manag 5:72

Barnes R, Rosello M (2020) Fisheries and maritime security: understanding and enhancing the connection. In: Evans MD, Galani S (eds) Maritime security and the law of the sea. Edward Elgar Publishing, New York
Bateman IJ, Mace GM (2020) The natural capital framework for sustainably efficient and equitable decision making. Nat Sustain 3:1-8

Bax N, Novaglio C, Maxwell KE et al (2020a) Ocean resource use: building the coastal blue economy. Authorea. https:// doi.org/10.22541/au.160391057.79751584/v2

Bax N, Sands CJ, Gogarty G et al (2020b) Perspective: increasing blue carbon around Antarctica is an ecosystem service of considerable societal and economic value worth protecting. Glob Chang Biol. https://doi.org/10.1111/gcb. 15392

Beaumont NJ, Aanesen M, Austen MC et al (2019) Global ecological, social and economic impacts of marine plastic. Mar Pollut Bull 142:189-195

Bebbington J, Österblom H, Crona B et al (2019) Accounting and accountability in the Anthropocene. Accounting. Audit Account J. https://doi.org/10.1108/AAAJ-11-2018-3745

Bennett NJ, Cisneros-Montemayor AM, Blythe J et al (2019) Towards a sustainable and equitable blue economy. Nat Sustain. https://doi.org/10.1038/s41893-019-0404-1

Bidwell D (2017) Ocean beliefs and support for an offshore wind energy project. Ocean Coast Manag. https://doi.org/ 10.1016/j.ocecoaman.2017.06.012

Börjeson L, Höjer M, Dreborg K-H et al (2006) Scenario types and techniques: towards a user's guide. Futures. https://doi. org/10.1016/j.futures.2005.12.002

Boschetti F, Lozano-Montes H, Stelfox B (2020) Modelling regional futures at decadal scale: application to the Kimberley region. Sci Rep. https://doi.org/10.1038/s41598019-56646-X

Brundtland G (1987) Report of the world commission on environment and development: our common future. United Nations General Assembly document A/42/427

Buchholz P, Brandenburg T (2018) Demand, supply, and price trends for mineral raw materials relevant to the renewable energy transition wind energy, solar photovoltaic energy, and energy storage. Chemie Ing Tech 90:141-153

Buck BH, Nevejan N, Wille M et al (2017) Offshore and multiuse aquaculture with extractive species: seaweeds and bivalves. In: Buck BH, Langan R (eds) Aquaculture perspective of multi-use sites in the open ocean. Springer, Cham, pp 23-69

Business Network for Offshore Wind (2019) Leadership 100 workplan. https://www.offshorewindus.org/wp-content/ uploads/2019/06/L100WhitePaperJun.3.2019.pdf

Campbell LM, Gray NJ, Fairbanks L et al (2016) Global oceans governance: new and emerging issues. Annu Rev Environ Resour 41:517-543

Carmody C (2012) Considering future generations Sustainability in theory and practice. Econ Round-up 3:65

Caswell BA, Klein ES, Alleway HK et al (2020) Something old, something new: historical perspectives provide lessons for blue growth agendas. Fish Fish 2:68

Chen W, Ruldoph D, Haggett C et al. (2014) D6.4 A framework for describing the social impacts with concrete examples that apply for the Canary Islands. EU FP7 Tropos Project

Chiaramonti D, Maniatis K (2020) Security of supply, strategic storage and Covid19: which lessons learnt for renewable and recycled carbon fuels, and their future role in decarbonizing transport? Appl Energy 271:115216 
Choi YR (2017) The Blue Economy as governmentality and the making of new spatial rationalities. Dialogues Hum Geogr 7:37-41

Chopin T (2013) Aquaculture, integrated multi-trophic (IMTA). In: Christou P, Savin R, Costa-Pierce BA, Misztal I, Whitelaw CBA (eds) Sustainable food production. Springer, New York

Cisneros-Montemayor AM, Moreno-Báez M, Voyer M et al (2019) Social equity and benefits as the nexus of a transformative Blue Economy: a sectoral review of implications. Mar Policy. https://doi.org/10.1016/j.marpol.2019. 103702

Claudet J, Bopp L, Cheung WW et al (2020) A roadmap for using the UN Decade of ocean science for sustainable development in support of science, policy, and action. One Earth 2(1):34-42

Cohen MJ (2020) Does the COVID-19 outbreak mark the onset of a sustainable consumption transition?

Colvin RM, Witt GB, Lacey J (2016) Approaches to identifying stakeholders in environmental management: insights from practitioners to go beyond the 'usual suspects'. Land use policy 52:266-276

Copping AE, Sather NK, Hanna L et al (2016) Annex IV 2016 state of the science report: environmental effects of marine renewable energy development around the world. Report for Ocean Energy System (OES)

Dal Bó E (2006) Regulatory capture: a review. Oxf Rev Econ Policy 22(2):203-225

Dalton G, Bardócz T, Blanch M et al (2019) Feasibility of investment in Blue Growth multiple-use of space and multi-use platform projects; results of a novel assessment approach and case studies. Renew Sustain Energy Rev 107:338-359

Dede C (2009) Immersive interfaces for engagement and learning. Science 323:66-69

Duarte CM, Agusti S, Barbier E et al (2020) Rebuilding marine life. Nature 580:39-51

Duch-brown N, Mueller-langer F (2017) The economics of ownership, access and trade in digital data. Digit Econ Work Pap 2017-01; JRC Tech Reports

Dudley N, Jonas H, Nelson F et al (2018) The essential role of other effective area-based conservation measures in achieving big bold conservation targets. Glob Ecol Conserv 15:e00424

Dunstan PK, Bax NJ, Dambacher JM et al (2016) Using ecologically or biologically significant marine areas (EBSAs) to implement marine spatial planning. Ocean Coast Manag 121:116-127

Durden JM, Lallier LE, Murphy K et al (2018) Environmental Impact Assessment process for deep-sea mining in the Area'. Mar Policy 87:194-202

Egger M, Sulu-Gambari F, Lebreton L (2020) First evidence of plastic fallout from the North Pacific Garbage Patch. Sci Rep. https://doi.org/10.1038/s41598-020-64465-8

Ellis JI, Clark MR, Rouse HL, Lamarche G (2017) Environmental management frameworks for offshore mining: the New Zealand approach. Mar Policy 84:178-192

Ertör I, Hadjimichael M (2020) Blue degrowth and the politics of the sea: rethinking the blue economy. Sustain Sci 15:1-10
European Commission (2012) Blue Growth: opportunities for marine and maritime sustainable growth. Communication from the Commission to the European Parliament, the Council, the European Economic and Social Committee and the Committee of the Regions. Publications Office of the European Union

Farmery AK, Alexander KA, Anderson K et al (2020) Food for all: designing sustainable and secure future seafood systems. Authorea. https://doi.org/10.22541/au.160322471. $16891119 / \mathrm{v} 1$

Fischer M, Maxwell K, Frederiksen N et al (2020) A fair ocean future for earth's first peoples. Authorea. https://doi.org/10. 22541/au.160391058.89181791/v1

Fortunato S, Bergstrom CT, Börner K et al (2018) Science of science. Science 349:52

Fritsch D (2020) Investors and the blue economy. Responsible Investor Research

Galaz V, Crona B, Dauriach A et al (2018) Tax havens and global environmental degradation. Nat Ecol Evol. https:// doi.org/10.1038/s41559-018-0497-3

Garland M, Axon S, Graziano M et al (2019) The blue economy: identifying geographic concepts and sensitivities. Geogr Compass 13:e12445

Gee K (2010) Offshore wind power development as affected by seascape values on the German North Sea coast. Land use policy. https://doi.org/10.1016/j.landusepol.2009.05.003

Gjølberg M (2009) The origin of corporate social responsibility: global forces or national legacies? Socio-Econ Rev 7:605-637

Global Sustainable Investment Alliance (2018) Global sustainable investment review. http://www.gsi-alliance.org. Accessed 10 Feb 2020

Glover AG, Wiklund H, Chen C, Dahlgren TG (2018) Point of view: managing a sustainable deep-sea 'blue economy'requires knowledge of what actually lives there. Elife 7:e41319

Golden J, Virdin J, Nowacek D et al (2017) Making sure the blue economy is green. Nat Ecol Evol. https://doi.org/10.1038/ s41559-016-0017

Haas B, Mackay M, Novaglio C et al (2020) The future of ocean governance. Authorea. https://doi.org/10.22541/au. $160193487.70124607 / \mathrm{v} 1$

Hadjimichael M (2018) A call for a blue degrowth: unravelling the European Union's fisheries and maritime policies. Mar Policy 94:158-164

Halpern BS, Frazier M, Afflerbach J et al (2019) Recent pace of change in human impact on the world's ocean. Sci Rep $9: 1-8$

Hardin G (1968) The tragedy of the commons. Science 162:1243-1248

Harvey B, Bice S (2014) Social impact assessment, social development programmes and social licence to operate: tensions and contradictions in intent and practice in the extractive sector. Impact Assess Proj Apprais 32:327-335

Haward MG, Vince J (2008) Oceans governance in the twentyfirst century: managing the blue planet. Edward Elgar Publishing, New York

Heidenreich S (2016) Out of sight, out of mind? Controversy over offshore wind energy in Norway's news media. Sci Cult 25:449-472 
Hein JR, Mizell K, Koschinsky A, Conrad TA (2013) Deepocean mineral deposits as a source of critical metals for high-and green-technology applications: comparison with land-based resources. Ore Geol Rev 51:1-14

Hemer MA, Manasseh R, McInnes KL et al (2018) Perspectives on a way forward for ocean renewable energy in Australia. Renew Energy 127:733-745

Hoegh-Guldberg O, Lovelock C, Caldeira K et al (2019a) The ocean as a solution to climate change: Five cpportunities for action. Report. Washington, DC: World Resources Institute. Available online at http://www.oceanpanel.org/ climate

Hoegh-Guldberg O, Northrop E, Lubchenco J (2019b) The ocean is key to achieving climate and societal goals. Science. https://doi.org/10.1126/science.aaz4390

Hilger J, Hallstein E, Stevens AW, Villas-Boas SB (2019) Measuring willingness to pay for environmental attributes in seafood. Environ Resour Econ 73:307-332

International Energy Agency (2019) Tracking power. https:// www.iea.org/reports/tracking-power-2019. Accessed 10 Feb 2020

Jackson J, Kirby M, Berger WH et al (2001) Historical overfishing and the recent collapse of coastal ecosystems. Science. https://doi.org/10.1126/science.1059199

Jamieson D (2008) A companion to environmental philosophy. Wiley, New York

Jones PJS, Lieberknecht LM, Qiu W (2016) Marine spatial planning in reality: introduction to case studies and discussion of findings. Mar Policy 71:256-264

Jones DOB, Durden JM, Murphy K et al (2019) Existing environmental management approaches relevant to deep-sea mining. Mar Policy 103:172-181

Jouffray JB, Crona B, Wassénius E et al (2019) Leverage points in the financial sector for seafood sustainability. Sci Adv. https://doi.org/10.1126/sciadv.aax3324

Jouffray JB, Blasiak R, Norström AV et al (2020) The Blue Acceleration: the trajectory of human expansion into the ocean. One Earth. https://doi.org/10.1016/j.oneear.2019. 12.016

Kaldellis JK, Apostolou D, Kapsali M, Kondili E (2016) Environmental and social footprint of offshore wind energy. Comparison with onshore counterpart. Renew Energy 92:543-556

Kallis G, Kerschner C, Martinez-Alier J (2012) The economics of degrowth. Ecol Econ 82:172-180

Kelly R, Evans K, Alexander KA et al (forthcoming) Connecting to the oceans: supporting ocean literacy and public engagement. Rev Fish Biol Fish

Korpinen S, Andersen JH (2016) A global review of cumulative pressure and impact assessments in marine environments. Front Mar Sci 3:153

Kraemer A (2017) A sustainable ocean economy, innovation and growth: a G20 initiative. Center for International Governance Innovation. Policy Brief No. 113

Krelling AP, Williams AT, Turra A (2017) Differences in perception and reaction of tourist groups to beach marine debris that can influence a loss of tourism revenue in coastal areas. Mar Policy 85:87-99

Lacy P, Rutqvist J (2016) Waste to wealth: the circular economy advantage. Springer, Berlin
Laffoley D, Baxter JM, Amon DJ et al (2019) Eight urgent, fundamental and simultaneous steps needed to restore ocean health, and the consequences for humanity and the planet of inaction or delay. Aquat Conserv Mar Freshw Ecosyst. https://doi.org/10.1002/aqc.3182

Lagasco F, Collu M, Mariotti A et al. (2019) New engineering approach for the development and demonstration of a multi-purpose platform for the blue growth economy. In: ASME 2019 38th international conference on ocean, offshore and arctic engineering. American Society of Mechanical Engineers Digital Collection

Landon-Lane M (2018) Corporate social responsibility in marine plastic debris governance. Mar Pollut Bull 127:310-319

Lehmann I, Martin A, Fisher JA (2018) Why should ecosystem services be governed to support poverty alleviation? Philosophical perspectives on positions in the empirical literature. Ecol Econ 149:265-273

Levin LA, Mengerink K, Gjerde KM et al (2016) Defining "serious harm" to the marine environment in the context of deep-seabed mining. Mar Policy 74:245-259

Lim KH, Hu W, Nayga RM Jr (2018) Is Marine Stewardship Council's ecolabel a rising tide for all? Consumers' willingness to pay for origin-differentiated ecolabeled canned tuna. Mar Policy 96:18-26

Mayer LA (2006) Frontiers in seafloor mapping and visualization. Mar Geophys Res 27:7-17

Melbourne-Thomas J, Audzijonyte A, Brasier M et al (2020) Poleward bound: adapting to climate driven species redistribution. Authorea. https://doi.org/10.22541/au. $160435617.76868505 / \mathrm{v} 1$

Mickelson K (2019) Common heritage of mankind as a limit to exploitation of the global commons. Eur J Int Law. https:// doi.org/10.1093/ejil/chz023

Miller KA, Thompson KF, Johnston P, Santillo D (2018) An overview of seabed mining including the current state of development, environmental impacts, and knowledge gaps. Front Mar Sci 4:418

Nash KL, Cvitanovic C, Fulton EA et al (2017) Planetary boundaries for a blue planet. Nat Ecol Evol. https://doi.org/ 10.1038/s41559-017-0319-z

Nash KL, van Putten I, Alexander KA et al (2020) Ocean and society: feedbacks between human and ocean health. Authorea. https://doi.org/10.22541/au.160166568. 89566317

Nash KL, Alexander KA, Melbourne-Thomas J et al (forthcoming) Developing achievable alternate futures for key challenges during the UN decade of ocean science for sustainable development. Rev Fish Biol Fish

Nie M (2003) Drivers of natural resource-based political conflict. Policy Sci. https://doi.org/10.1023/b:olic. 0000017484.35981.b6

Nilsson M, Griggs D, Visbeck M (2016) Policy: map the interactions between Sustainable Development Goals. Nature 534:320-322

Northrop E, Konar M, Frost N et al (2020) Sustainable and Equitable Blue Recovery to the COVID-19 Crisis. Report. Washington, DC: World Resources Institute. http://www. oceanpanel.org/bluerecovery 
Nyström M, Jouffray JB, Norström AV et al (2019) Anatomy and resilience of the global production ecosystem. Nature. https://doi.org/10.1038/s41586-019-1712-3

O’Higgins T, O’Higgins L, O'Hagan AM, Ansong JO (2019) Challenges and opportunities for ecosystem-based management and marine spatial planning in the Irish Sea. In: Zaucha J, Gee K (eds) Maritime spatial planning. Palgrave Macmillan, Cham, pp 47-69

O'Leary BC, Winther-Janson M, Bainbridge JM et al (2016) Effective coverage targets for ocean protection. Conserv Lett 9:398-404

OECD (2016) The ocean economy in 2030. OECD Publishing, Paris

OECD (2019) Rethinking Innovation for a Sustainable Ocean Economy. OECD Publishing, Paris

Pandolfi JM, Bradbury RH, Sala E et al (2003) Global trajectories of the long-term decline of coral reef ecosystems. Science. https://doi.org/10.1126/science.1085706

Patil PG, Virdin J, Colgan CS et al (2018) Toward a blue economy: a pathway for Bangladesh's sustainable growth. World Bank

Pearlman JS, Bushnell M, Coppola L et al (2019) Evolving and sustaining ocean best practices and standards for the next decade. Front Mar Sci 6:277

Planque B, Mullon C, Arneberg P et al (2019) A participatory scenario method to explore the future of marine socialecological systems. Fish Fish 20(3):434-451

Pomeroy RS, Parks JE, Balboa CM (2006) Farming the reef: is aquaculture a solution for reducing fishing pressure on coral reefs? Mar Policy. https://doi.org/10.1016/j.marpol. 2004.09.001

Pörtner HO, Roberts D, Masson-Delmotte V et al (2019) IPCC special report on the ocean and cryosphere in a changing climate. IPCC Intergov Panel Clim Chang Geneva, Switz

Poulsen T, Lema R (2017) Is the supply chain ready for the green transformation? The case of offshore wind logistics. Renew sust energ rev 73:758-771

Ribeiro MC, Ferreira R, Pereira E, Soares J (2020) Scientific, technical and legal challenges of deep sea mining. A vision for Portugal. In: Conference report. Mar Policy. https://doi. org/10.1016/j.marpol.2018.11.001

Ripple WJ, Wolf C, Newsome TM (2019) World scientists' warning of a climate emergency. Bioscience. https://doi. org/10.1093/biosci/biz088

Robinson JB (1990) Futures under glass: a recipe for people who hate to predict. Futures 22:820-842. https://doi.org/10. 1016/0016-3287(90)90018-D

Rockström J, Gaffney O, Rogelj J et al (2017) A roadmap for rapid decarbonization. Science. https://doi.org/10.1126/ science.aah3443

Roesijadi G, Copping AE, Huesemann MH et al. (2008) Techno-economic feasibility analysis of offshore seaweed farming for bioenergy and biobased products. Battelle Pacific Northwest Div Rep Number PNWD-3931 1e115

Santos CF, Agardy T, Andrade F et al (2020) Integrating climate change in ocean planning. Nat Sustain 5:1-12

Schatz VJ (2019) The international legal framework for postBrexit EEZ fisheries access between the United Kingdom and the European Union. Int J Mar Coast Law 1:1-30
Schroeder P, Anggraeni K, Weber U (2019) The relevance of circular economy practices to the sustainable development goals. J Ind Ecol 23:77-95

Smith D, Haward M, McGee J et al (2020) Sharing our oceans fairly: improving international relations around ocean issues. Authorea. https://doi.org/10.22541/au.160441713. 30169042/v1

Sondak CFA, Ang PO, Beardall J et al (2017) Carbon dioxide mitigation potential of seaweed aquaculture beds (SABs). J Appl Phycol 29:2363-2373

Spijkers J, Morrison TH, Blasiak R et al (2018) Marine fisheries and future ocean conflict. Fish Fish 19(5):798-806

Stead SM (2019) Using systems thinking and open innovation to strengthen aquaculture policy for the United Nations Sustainable Development Goals. J Fish Biol 94(6):837-844

Steffen W, Richardson K, Rockström J et al (2015) Planetary boundaries: guiding human development on a changing planet. Science 347:6223

Steurer R (2010) The role of governments in corporate social responsibility: characterising public policies on CSR in Europe. Policy Sci 43:49-72

Stuiver M, Soma K, Koundouri P et al (2016) The governance of multi-use platforms at sea for energy production and aquaculture: challenges for policy makers in European Seas. Sustain. https://doi.org/10.3390/su8040333

Taylor P (2014) The common heritage of mankind: a bold doctrine kept within strict boundaries. The wealth of the commons: a world beyond the market and state

Teske S, Florin N, Dominish E, Giurco D (2016) Renewable energy and deep-sea mining: supply, demand and scenarios. Report prepared by ISF for J.M. Kaplan Fund, Oceans 5 and Synchronicity Earth

Thiele T, Gerber LR (2017) Innovative financing for the High Seas. Aquat Conserv Mar Freshw Ecosyst Freshw Ecosyst. https://doi.org/10.1002/aqc.2794

Tian N, Fleurant A, Kuimova A et al. (2019) Trends in World Military Expenditure, 2018. SIPRI Fact Sheet

Toro N, Robles P, Jeldres RI (2020) Seabed mineral resources, an alternative for the future of renewable energy: a critical review. Ore Geol Rev 10:3699

Trebilco R, Fleming A, Hobday AJ et al (2020) Warming world, changing ocean: adaptation and mitigation for resilient marine systems. Authorea. https://doi.org/10.22541/au. $160193478.81087102 / \mathrm{v} 1$

UN Department of Economic and Social Affairs, Population Division (2019). World Population Prospects 2019: Highlights (ST/ESA/SER.A/423)

UNEP (2014) Valuing plastics: the business case for measuring, managing and disclosing plastic use in the consumer goods industry

UNEP \& GEF-STAP (2014) Marine Spatial Planning in practice-transitioning from planning to implementation. In: Thomas HL, Olsen S, Vestergaard O (eds) An analysis of global Marine Spatial Planning experiences. UNEP Nairobi, pp 36

UNESCO (2019) United Nations Decade of Ocean Science for Sustainable Development. https://www.oceandecade.org/. Accessed 10 Oct 2019

Van Dover CL, Aronson J, Pendleton L et al (2014) Ecological restoration in the deep sea: desiderata. Mar Policy 44:98-106 
Vanderklift MA, Marcos-Martinez R, Butler JR et al (2019) Constraints and opportunities for market-based finance for the restoration and protection of blue carbon ecosystems. Mar Pol 107:103429

Vince J, Hardesty BD (2017) Plastic pollution challenges in marine and coastal environments: from local to global governance. Restor Ecol 25:123-128

Vincent K, Carter S, Steynor A et al (2020) Addressing power imbalances in co-production. Nat Clim Chang. https://doi. org/10.1038/s41558-020-00910-w

Voyer DM, van Leeuwen DJ (2019) 'Social license to operate' in the Blue Economy. Resour Policy. https://doi.org/10. 1016/j.resourpol.2019.02.020

Voyer DM, Quirk G, McIlgorm A, Azmi K (2018) Shades of blue: what do competing interpretations of the Blue Economy mean for oceans governance? J Environ Policy Plan 20(5):595-616

Wabnitz CC, Blasiak R (2019) The rapidly changing world of ocean finance. Mar Pol 107:103526

Wilkinson MD, Dumontier M, Aalbersberg IJ et al (2016) The FAIR Guiding Principles for scientific data management and stewardship. Sci Data. https://doi.org/10.1038/sdata. 2016.18

Winder GM, Le Heron R (2017) Assembling a Blue Economy moment? Geographic engagement with globalizing biological-economic relations in multi-use marine environments. Dialogues Hum Geogr 7:3-26

Winther JG, Dai M, Rist T et al (2020) Integrated ocean management for a sustainable ocean economy. Nat Ecol Evol $3: 1-8$

World Bank (2017) The potential of the Blue Economy. Increasing long-term benefits of the sustainable use of marine resources for Small Island Developing States and Coastal Least Developed Countries. World Bank Publisher

Willis KJ, Puskic P, Anderson K et al (2020) Cleaner seas: reducing marine pollution. Authorea.https://doi.org/10. 22541/au.160382467.73347721/v1

Yoerger DR, Bradley AM, Jakuba M et al (2007) Autonomous and remotely operated vehicle technology for hydrothermal vent discovery, exploration, and sampling. Oceanography 20:152-161

Zanuttigh B, Angelelli E, Kortenhaus A et al (2016) A methodology for multi-criteria design of multi-use offshore platforms for marine renewable energy harvesting. Renew Energy 85:1271-1289

Publisher's Note Springer Nature remains neutral with regard to jurisdictional claims in published maps and institutional affiliations. 